Int. J. Dev. Biol. 48: 339-342 (2004)

Short Communication

\title{
Developing chick embryos express a protein which shares homology with the nuclear pore complex protein Nup88 present in human tumors
}

\author{
JOSÉ SCHNEIDER ${ }^{1,2}{ }^{2}$ RAFAEL LINARES ${ }^{1}$, FERNANDO MARTÍNEZ-ARRIBAS ${ }^{2}$, MARÍA-DOLORES MORAGUES ${ }^{3}$, \\ MARÍA-JOSÉ NÚÑEZ-VILLAR ${ }^{2}$, MARÍA-ANGUSTIAS PALOMAR ${ }^{1}$ and JOSÉ PONTÓN ${ }^{*}, 4$ \\ ${ }^{1}$ Department of Health Sciences, Faculty of Health Sciences, Rey Juan Carlos University, Madrid, ${ }^{2}$ Tejerina Foundation, Madrid, ${ }^{3}$ Department \\ of Nursing I and ${ }^{4}$ Department of Immunology, Microbiology and Parasitology, Faculty of Medicine and Dentistry, \\ University of the Basque Country, Bilbao, Spain
}

\begin{abstract}
Nup88 is a nuclear pore complex protein which is overexpressed in a variety of human tumors of the stomach, colon, liver, pancreas, breast, lung, ovary, uterus, prostate and kidney. A monoclonal antibody crossreacting with the yeast Candida albicans and Nup88 was used to investigate the expression of cross-reactive antigens in chick embryos, in an attempt to identify an experimental model for studying the role played by Nup88 during cell development and differentiation. All cells in the trilaminar embryo were labeled with the antibody, but as development advanced and organogenesis was completed, expression of the corresponding antigen became more restricted. Thus, some structures continued to be intensely labeled (skin epithelium, oropharyngeal endothelium, perichondral mesenchymal tissue), whereas others ( muscular tissue, vascular endothelium, respiratory endothelium, digestive tract mucosa, peripheral nerves, medullary white matter and the retinal axons) were more moderately stained. No immunoreactivity was observed in the medullary grey matter or cartilage. A specific band of $53 \mathrm{kDa}$ observed by Western blotting of chick embryo extracts suggested that the chicken antigen recognized by the monoclonal antibody is the homologue of human Nup88, which is associated with the high proliferation and low differentiation of tumor cells. The present results indicate that the role of Nup88 in cell differentiation and organ development could be fruitfully investigated using the developing chick embryo as an experimental model.
\end{abstract}

KEY WORDS: chick embryo, antigen expression, Nup88, human tumor, monoclonal antibody C7

In a previous report (Schneider et al., 1998), we described a cross-reactivity between the yeast Candida albicans and human ovarian carcinoma using two monoclonal antibodies originally developed against yeast cell wall mannoproteins (Pontón et al., 1993). Further studies revealed that this cross-reactivity was elicited by the nuclear pore complex protein Nup88 (Martínez et al., 1999), whose gene was cloned by Fornerod et al. (1997a). Immunohistochemical analysis of a panel of tumors using a polyclonal antibody to Nup88 revealed that virtually all examined tumors expressed Nup88, whereas their benign counterparts did not, or did so only very faintly (Gould et al., 2000). The role played by Nup88 in human tumorigenesis is however still obscure, although two recent publications seem to indicate that it is related to the aggressiveness and metastatic potential of cultured melanoma cells and clinical colon carcinoma (Zhang et al., 2002; Emterling et al., 2003), and to low differentiation and high proliferation of breast cancer (Agudo et al., 2004).
From a phylogenetic point of view, yeast and man are very distant and quite unrelated. Therefore, we anticipated that organisms closer to human, such as the mouse or chicken, would probably show a similar pattern of cross-reactivity with human cancer cells as the one described for $C$. albicans. If so, these organisms would constitute an excellent experimental model for studying the role played by Nup88, especially during embryologic development, since many of the fundamental molecular processes which take place during development are mimicked by cancer cells during tumorigenesis. We could not study the mouse embryo with our mouse-derived monoclonal antibodies for obvious reasons, but the chick embryo instead did not show any disturbing background reactivity during preliminary studies with the different monoclonal antibodies derived from related hybrido-

Abbreviations used in this paper: Nup, nuclear pore.

\footnotetext{
*Address correspondence to: Dr. José Pontón. Departamento de Inmunología, Microbiología y Parasitología, Facultad de Medicina y Odontología, Universidad del País Vasco, Apartado 699, E-48080 Bilbao, Vizcaya, Spain. Fax: +34-94-601-3400. e-mail: oipposaj@Ig.ehu.es.
} 

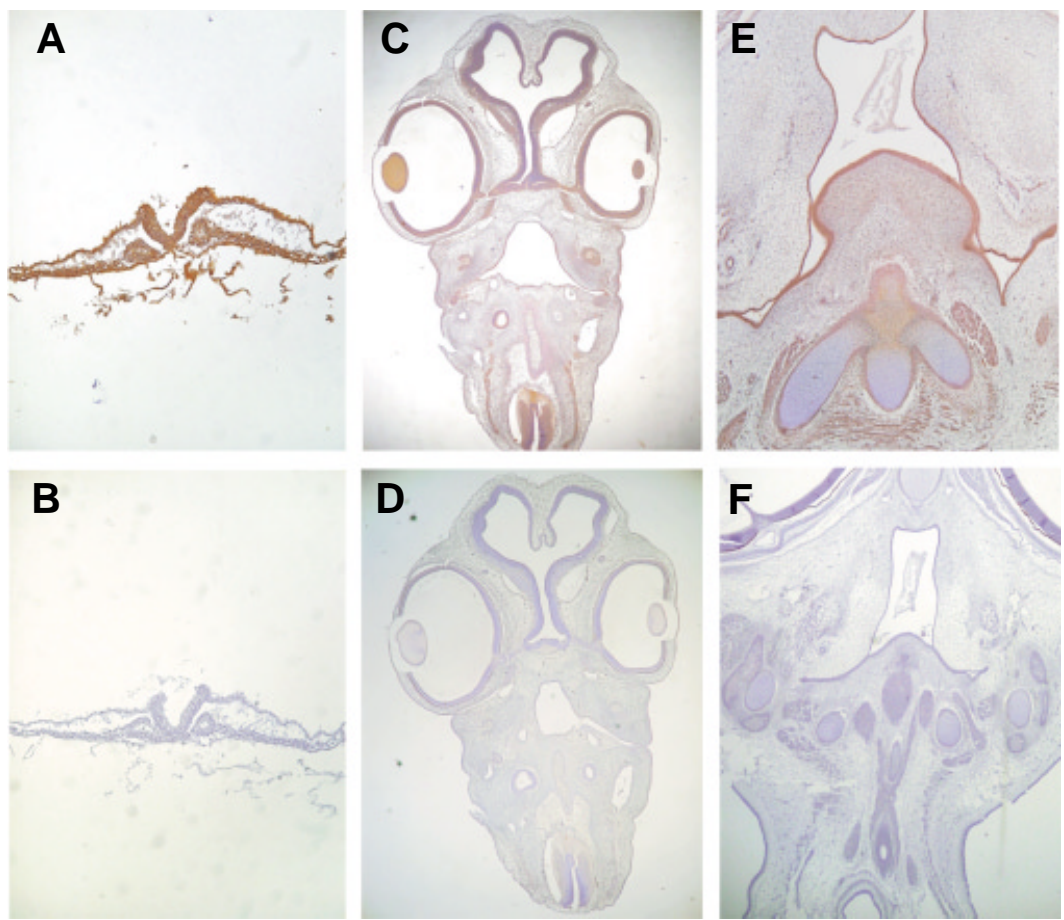

Fig. 1. Reactivity of the chick embryo with the $\mathbf{C} 7$ monoclonal antibody and corresponding negative controls at various stages of development. Antibody dilution 1:100. Streptavidin-biotin-peroxidase. Magnification: X250. (A,B) Trilaminar embryo, stage 8 (26-29 hours). (C,D) Stage 27 (5-5.5 days). (E,F) Stage 34 (8 days).

mas developed against yeast antigens. One of them, C7, closely related to the $\mathrm{C} 6$ antibody which we previously reported (Schneider et al., 1998), showed the best pattern of reactivity both in human cancer and in the chick embryo. Monoclonal antibody C7 is an IgM directed against an epitope expressed on a mannoprotein of $>200$ kDa from a variety of Candida species which has been shown to exert direct candidacidal activity (Moragues et al., 2003). In this report, we have investigated the expression of antigens recognized by monoclonal antibody $\mathrm{C} 7$ in chick embryos, in an attempt to identify an experimental model for studying the role played by Nup88 during development and differentiation.

At early stages of development (trilaminar embryo), all cells showed a strong reaction with the $\mathrm{C} 7$ antibody (Fig. 1A). However, as development advanced and organogenesis was completed, some structures retained a strong staining pattern, whereas others lost reactivity (Fig. $1 \mathrm{C}$ and $\mathrm{E}$ ). In Table 1 we summarize the organs which retained reactivity after all of them had completed their development, graded by intensity of staining, together with those that had lost reactivity.

Studies of human tumors using the same technique revealed that some, such as ovarian cancer (Fig. 2A), showed a granular staining, with marked perinuclear accumulation, whereas others, such as oral squamous carcinomas, showed a more diffuse cytoplasmic pattern (Fig. 2B). This paradoxical finding of a protein primarily located at the nuclear envelope may be due to its overproduction and shedding into the cytoplasm, as others have previously reported (Bastos et al., 1997). In fact, Nup88 is located distally on the filaments of the cytoplasmic face of the nuclear pore. The staining pattern observed in the chick embryo corresponded rather to the more diffuse, cytoplasmic distribution of the reaction.
A specific band of $53 \mathrm{kDa}$ was observed by Western blotting of chick embryo extracts (Fig. 3A, lane 1). This band had a molecular weight similar to that shown by a human breast tumor extract (Fig. 3A, lane 2), suggesting that the antigen recognized by the $\mathrm{C} 7$ monoclonal antibody in chicken is closely related to the human one. A monoclonal antibody against actin was used to confirm that the protein content of the different lanes was equivalent and to verify that the $53 \mathrm{kDa}$ protein was not actin (data not shown). Western blots performed with a monoclonal antibody against Nup88 showed a band of $88 \mathrm{kDa}$ in extracts from HeLa cells (Fig. 3A, lane 3). However, monoclonal antibody $\mathrm{C} 7$ reacted with components of 88,55 and $53 \mathrm{kDa}$ in extracts from HeLa cells (Fig. $3 \mathrm{~A}$, lane 4), suggesting that the $53 \mathrm{kDa}$ component corresponds to a specific Nup88 degradation product. Confirmation that the antigens recognized in chicken and human tissues by monoclonal antibody C7 were Nup88 was obtained with a recombinant fragment of $27 \mathrm{kDa}$ from Nup88 obtained in Escherichia coli. Both the polyclonal anti-Nup88 antibody and the $\mathrm{C} 7$ monoclonal antibody reacted strongly with the recombinant protein (Fig. 3B).

The precise role of Nup88 is largely unknown. It forms part of the CAN/Nup complex, which in its turn is located in the cytoplasmic filaments of the nuclear pore complex. Nup88 is associated to the Nup214/ CAN nucleoporin in such a way that it is no longer detectable when the latter is deleted (Fornerod et al., 1997a). This close dependence allows us to speculate indirectly about the possible function of Nup88 through the known facts about the role of Nup214. Deletion experiments involving the latter elicit a phenotype showing defective protein transport through the nuclear membrane (in both directions), as well as cell cycle arrest in G2 (Fornerod et al., 1997b). Nup214-overexpression, on the other hand, is associated with cell cycle arrest in G0, mRNA accumulation in the nucleus and apoptosis (Boer et al., 1998). It therefore seems that Nup214 has some crucial function related to the correct progression of the cell cycle. The exact role played by Nup88 in this context is unclear at the present moment. Its rat

TABLE 1

\section{NUP88 ANALOGUE PROTEIN EXPRESSION IN CHICK EMBRYO STRUCTURES AFTER COMPLETE ORGAN DEVELOPMENT}

\begin{tabular}{lc} 
Tissue & Staining intensity \\
\hline Skin epithelium & +++ \\
Oropharyngeal endothelium & ++ \\
Perichondral mesenchymal tissue & ++ \\
Muscle & + \\
Vascular endothelium & + \\
Respiratory endothelium & + \\
Digestive tract mucosa & + \\
Peripheral nerves & + \\
Medullary white matter & + \\
Retinal axons & + \\
Medullary grey matter & - \\
Cartilage & - \\
\hline
\end{tabular}

C7 Monoclonal antibody. Streptavidin-biotin-peroxidase technique. 

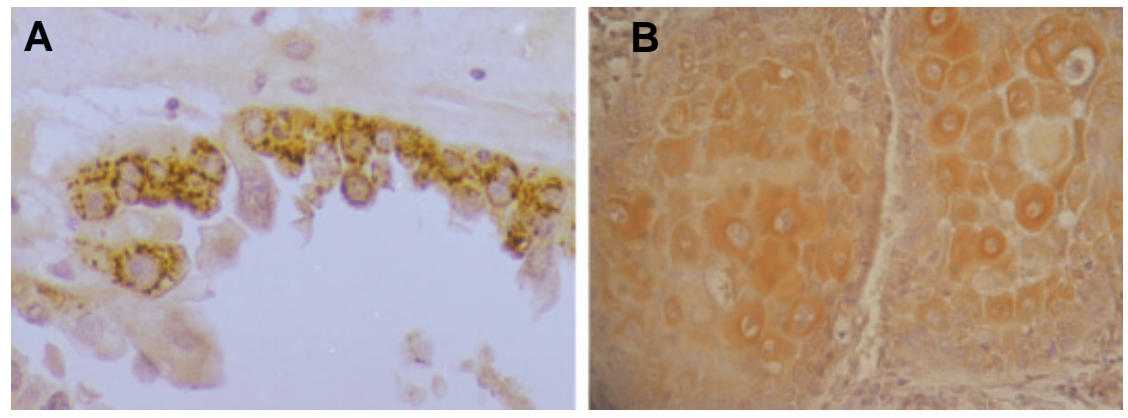

Fig. 2. Immunohistochemical reaction of the $\mathbf{C 7}$ monoclonal antibody with human tumors. (A) Ovarian epithelial carcinoma. Granular, perinuclear reaction pattern. (B) Oral squamous carcinoma. Smooth cytoplasmic pattern. Magnification: X 400.

homologue, Nup84, is indispensable for the rearrangement of the cytoplasmic fraction of the nuclear pore complex (Bastos et al., 1997). Its yeast ( Saccharomyces cerevisiae) homologue, Nup82, on the other hand, is similarly important for mRNA transport to the cytoplasm. Some hints regarding the similarity, or close association of roles shared by Nup214 and Nup88 are given by recent research on their respective expression in human cancer. In fact, the CAN/Nup214 complex is fused to the SET protein, which plays a key role in leukemogenesis (Fornerod et al., 1996).

We have shown that Nup88 is expressed in tumor cells (Martínez et al., 1999) as well as in virtually all kinds of solid human tumors, and much less so, or not at all, in benign or premalignant tissues (Gould et al., 2000). Moreover, all our studies performed up to date on a variety of human tumors show that enhanced expression of Nup88 is linked to increased tumor

A

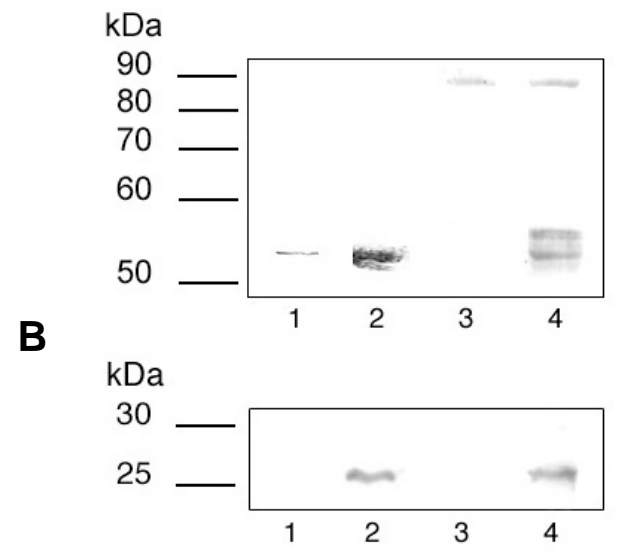

Fig. 3. Reactivity of $\mathbf{C 7}$ and anti-Nup88 antibodies by Western blotting. (A) Western blots of $10 \%$ slab gels loaded with a chick embryo extract (lane 1), a human breast tumor extract (lane 2) and HeLa cells extract (lanes 3 and 4) with monoclonal antibodies C7 (lanes 1, 2 and 4) and anti-Nup88 (lane 3). (B) Western blots of $10 \%$ slab gels loaded with extracts from E. coli cells containing the recombinant plasmid pTriEx-1 (Nup88-308) under basal (lanes 1 and 3) or IPTG induced expression (lanes 2 and 4). Lanes 1 and 2 were stained with polyclonal anti-Nup88 antibody and lanes 3 and 4 with monoclonal antibody C7. Molecular masses of standard proteins are listed to the left of the gel. aggressiveness (Zhang et al., 2002; Emterling et al., 2003). Along this line, in a recent report by our group on breast cancer (Agudo et al., 2004), we have been able to show that Nup88 mRNA overexpression is very significantly associated with all known biological and clinical features which are characteristic of a more aggressive phenotype, and in particular with those related to a lower degree of differentiation and a higher rate of proliferation.

Although the chicken homologue of Nup88 has not been cloned, the fact that there is a structurally associated homologue in the rat and yeast suggests that Nup88 has been highly conserved throughout phylogeny. Our finding of a band of very similar weight compared to its human counterpart in our Western-blots seems to indicate that the chicken homologue of Nup88 may be closely related to it.

In the present report, we have shown that Nup88 is expressed in a wide variety of cells at the earliest (most undifferentiated) stages of embryological differentiation. As organogenesis advances, the expression of Nup88 becomes more organ-specific and selective, suggesting that Nup88 may play a key role in proliferation and differentiation events, not only during tumorigenesis, but also during development. Further studies using the C7 monoclonal antibody and the developing chick embryo may contribute to improving our understanding of the role of Nup88 in both cell differentiation and organ development.

\section{Experimental Procedures}

\section{Embryos}

Chick embryos at various stages of development, from the trilaminar embryo stage until stages representing completed organogenesis were obtained after incubation of eggs at $37^{\circ} \mathrm{C}$. Embryos were removed from the eggs and the adhering yolk was cleaned off using fine dissecting needles. The cleaned embryos were studied by means of immunohistochemistry and Western-blotting using the $\mathrm{C} 7$ antibody.

\section{Human tumors}

For comparative purposes, several human tumors (64 ovarian and 34 oropharyngeal cancers) were also studied by means of immunohistochemistry using the $\mathrm{C} 7$ antibody. Western blotting was performed likewise on a protein pool from three different breast cancers.

\section{Recombinant Nup88 and antibodies}

Two recombinant fragments of human Nup88 protein were used. The first recombinant fragment (Nup88-259) was produced according to Martínez et al. (1999). Primers 5'-AGCAGTCGACCCAAGATGGCG-3' and 5'ATGCCACTACTCGAGC TTTGCCG-3' were used to amplify a 783-bp fragment from the Nup88 open reading frame (nucleotides minus 5 to 778) by PCR and it was cloned into pGEX4T-1 expression vector in Sall-Xhol sites (Amersham-Pharmacia Biotech, Uppsala, Sweden). The fusion protein GST-Nup88-259 was expressed in BL21 Escherichia coliand purified following the protocol described by Smith and Johnson (1988). A polyclonal antiserum against Nup88 was obtained from rabbits injected with the fusion protein (Martínez et al., 1999).

The second fragment (Nup88-308) contained the first 308 aminoacids of the N-terminal extreme of the human Nup88 protein. Primers 5'-CATGCCATGGCGGCCGCCGAAGGCCC-3' and 5'-CCCCAAGCTTACCATAGTTATCTTCAGCCG CA-3' were used to amplify a 924-bp fragment from the Nup88 open reading 
frame (nucleotides 1-924) by PCR and it was cloned into pTriEx-1 TM expression vector (Novagen, Merck KGaA, Darmstadt, Germany) in NcolHindll sites. This plasmid was transferred into Tuner ${ }^{\mathrm{TM}}$ cells (Novagen) to obtain the recombinant protein after induction with 0.5 mM IPTG (isopropylB-D-galactopyranoside).

Monoclonal antibody $\mathrm{C} 7$ was produced following standard methods with splenocytes from BALB/c mice immunized by intraperitoneal injections of a $C$. albicans high molecular weight stress mannoprotein recognized by salivary slgA (Moragues et al., 2003). Animal studies were performed in accordance with the guidelines of the Department of Agriculture of the Basque Government. The monoclonal antibody was purified from ascites fluid by affinity chromatography on an ImmunoPure $\AA$ IgM purification kit (Pierce, Rockford, IL), essentially as described by the manufacturer. The purified antibody was dialyzed against PBS and filter sterilized before use.

Monoclonal antibodies against Nup88 and actin were commercially available and they were purchased from BD Biosciences (Palo Alto, CA, USA) and Sigma Chemical Co., (St. Louis, Mo. USA), respectively.

\section{Immunohistochemistry}

The immunohistochemical procedure has been extensively described elsewhere (Schneider etal., 1998; Martínez etal., 1999; Gould etal., 2000). Briefly, $5 \mu \mathrm{m}$ sections were obtained from paraffin-embedded chick embryos and human tumors and mounted on poly-L-lysine coated slides. The immunohistochemical kit was always the same, to ensure uniformity of results (Histostain-SP, Zymed, San Francisco, Ca., USA). The antibody used was our own mouse monoclonal $\mathrm{C} 7$, diluted at 1:100. We employed the heat-induced antigen retrieval (HIER) technique developed at Zymed laboratories, as described on the data sheet accompanying their antibodies. The slides were deparaffinised in three xylene baths, 5 min each, and then rehydrated in phosphate-buffered saline (PBS) for $10 \mathrm{~min}$ after passages through graded ethanol (100\%, 96\%, 70\%), 3 min each. Afterwards, the preparations were pretreated for antigen retrieval (see above), incubated with blocking serum (component $1 \mathrm{~A}$ of the kit) for $10 \mathrm{~min}$, and subsequently with the prediluted antibody for $1 \mathrm{~h}$ at room temperature. The slides were then washed in PBS three times for $3 \mathrm{~min}$, after which the second, biotinylated bridge antibody was applied (component 1B of the kit) for $10 \mathrm{~min}$. Following three washes in PBS, $3 \mathrm{~min}$ each, the slides were incubated with the streptavidin-peroxidase complex (component $1 \mathrm{C}$ of the kit) for $10 \mathrm{~min}$, washed again in PBS and stained with Diamino-benzidine. They were then counterstained with hematoxylin for $30 \mathrm{~s}$ and mounted.

\section{Western-blotting}

Fresh tissues (10-20 chick embryos at various stages of development or $1 \mathrm{~g}$ of tumor tissue) or HeLa cells were homogenized in Tris- $\mathrm{HCl}$ at $\mathrm{pH}$ 6.8 and the protein extracts were separated by electrophoresis in SDS-10\% polyacrylamide gels according to Laemmli (1970). The proteins $(15-20 \mu \mathrm{g}$ per lane) were electroblotted onto Immobilon® membrane (Millipore) in a semi-dry blotter at $2.5 \mathrm{~mA} / \mathrm{cm}^{2}$ for $60 \mathrm{~min}$, and the transfer was checked by staining the membrane with Ponceau-S solution. The membrane was then dried and afterwards saturated in Tris buffer-saline (TBS) with $8 \%$ skimmed milk powder for $1 \mathrm{~h}$ at $37^{\circ} \mathrm{C}$, in order to completely block unspecific antigenic determinants which might cross-react with the study antibody. The blot was incubated with $\mathrm{C} 7$ antibody diluted 1:20 in TBS-skimmed milk, for $2 \mathrm{~h}$ at $37^{\circ} \mathrm{C}$, washed three times in TBS- $0.05 \%$ Tween 20 , and reincubated with horseradish peroxidase conjugated anti-mouse IgM antibody diluted 1:200 in TBS-skimmed milk, for $1 \mathrm{~h}$ at $37^{\circ} \mathrm{C}$. Prior to staining, the membrane was washed again in TBS, and afterwards incubated with TBS + 4-chloronaphtol + hydrogen peroxide for $30 \mathrm{~min}$ in complete darkness. The reaction was stopped by immersion of the membrane in distilled water, and the membrane was dried.

\section{Acknowledgments}

We are indebted to Dr. Jose Manuel Aguirre for providing the oral squamous cell carcinoma samples studied and to Dr. Carlos Matute for providing the monoclonal antibody against actin.
This investigation was supported by grants P1020432 from Fondo de Investigación Sanitaria, PIPR-02-19 from Universidad Rey Juan Carlos, 9/UPV 0093.327-13550/2001 from the Universidad del País Vasco and PM99-0033 from the Dirección General de Enseñanza Superior $e$ Investigación Científica from the Spanish Ministerio de Educacióny Cultura.

\section{References}

AGUDO, D., GOMEZ-ESQUER, F., MARTINEZ-ARRIBAS, F., NUÑEZ-VILLAR, M.J., LUCAS, A.R., POLLAN, M. and SCHNEIDER, J. (2004) Nup88-mRNA overexpression is associated with high aggressiveness of breast cancer. Int. J. Cancer 109:717-720.

BASTOS, R., RIBAS, D.P., ENARSON, M., BODOOR, K. and BURKE, B. (1997). Nup84, a novel nucleoporin that is associated with CAN/Nup214 on the cytoplasmic face of the nuclear pore complex. J. Cell. Biol. 137:989-1000.

BOER, J., BONTEN-SURTEL, J. and GROSVELD, G. (1998). Overexpression of the nucleoporin CAN/NUP214 induces growth arrest, nucleocytoplasmic transport defects, and apoptosis. Mol. Cell. Biol. 18:1236-1247.

EMTERLING, A., SKOGLUND, J., ARBMAN, G., ZHANG, H., SCHNEIDER, J., EVERTSON, S., CARSTENSEN, J. and SUN, X.F. (2003). Clinicopathological significance of Nup88 expression in patients with colorectal cancer. Oncology 64:361-369

FORNEROD, M., BOER, J., VAN BAAL, S., MORREAU, H., and GROSVELD, G. (1996). Interaction of cellular proteins with the leukemia specific fusion proteins DEK-CAN and SET-CAN and their normal counterpart, the nucleoporin CAN. Oncogene 13:1801-1808.

FORNEROD, M., VAN DEURSEN, J., VAN BAAL, S., REYNOLDS, A., DAVIS, D., MURTI, K., FRANSEN, J. and GROSVELD, G. (1997a). The human homologue of yeast CRM1 is in a dynamic subcomplex with CAN/Nup214 and a novel nuclear pore component Nup88. EMBO J. 16:807-816,

FORNEROD, M., VAN BAAL, S., VALENTINE, B., SHAPIRO, D.N. and GROSVELD, G. (1997b). Chromosomal localization of genes encoding CAN/Nup214-interacting proteins. Human CRM1 localizes to 2p16, whereas Nup88 localizes to 17p13 and is physically linked to SF2p32. Genomics 42:538-540.

GOULD, V.E., MARTíNEZ, N., ORUCEVIC, A., SCHNEIDER, J. and ALONSO, A. (2000). A novel, nuclear pore-associated, widely distributed molecule overexpressed in oncogenesis and development. Am. J. Pathol. 157:1605-1613.

LAEMMLI, U.K. (1970) Cleavage of structural proteins during the assembly of the head of bacteriophage T4. Nature 227:680-685.

MARTÍNEZ, N., ALONSO, A., MORAGUES, D., PONTÓN, J. and SCHNEIDER, J. (1999). The nuclear pore complex protein Nup88 is overexpressed by tumor cells. Cancer Res. 59:5408-5411.

MORAGUES, M.D., OMAETXEBARRIA, M.J., ELGUEZABAL, N., SEVILLA, M.J. CONTI, S., POLONELLI, L. and PONTÓN, J. (2003). A monoclonal antibody directed against a Candida albicans cell wall mannoprotein exerts three anti- $C$. albicans activities. Infect. Immun. 71:5273-5279.

PONTON, J., MAROT-LEBLOND, A., EZKURRA, P., BARTUREN, B., ROBERT, R. and SENET, J.M. (1993). Characterization of Candida albicans cell wall antigens with monoclonal antibodies. Infect. Immun. 61:4842-4847.

SCHNEIDER, J., MORAGUES, D., MARTÍNEZ, N., ROMERO, H., JIMÉNEZ, E. and PONTÓN, J. (1998). Cross reactivity between Candida albicans and human ovarian carcinoma as revealed by monoclonal antibodies PA10F and C6. Br. J. Cancer. 77:1015-1020.

SMITH, D.B. and JOHNSON, K.S. (1988). Single-step purification of polypeptides expressed in Escherichia coli as fusions with glutathione S-transferase. Gene (Amst.) 67: 1:31-40.

ZHANG, H., SCHNEIDER, J. and ROSDAHL, I. (2002). Expression of p16, p27, p53 and Nup88 proteins in matched primary and metastatic melanoma cells. Int. J. Oncol. 21:43-48.

Received: September 2003

Reviewed by Referees: November 2003 Modified by Authors and Accepted for Publication: May 2004 